\title{
A RELAÇÃO FAMÍLIA E INSTITUIÇÕES DE EDUCAÇÃO INFANTIL: IMPLICAÇÕES SOBRE O ENSINO DE FAMÍLIA PARA AS CRIANÇAS PEQUENAS
}

\author{
Suélen Cristiane Marcos \\ Universidade Estadual Paulista - FCT - UNESP. Programa de Pós Graduação em Educação E-mail: ssucris@hotmail.com
}

\begin{abstract}
RESUMO
Este artigo é fruto de uma pesquisa de Mestrado que teve como objetivo geral avaliar as concepções de família presentes nos planos diretores de Instituições de Educação Infantil, para saber o que pensam os educadores sobre as famílias das crianças e se o valor que a elas atribuem interfere na relação família e instituições de Educação Infantil. Buscou-se também problematizar o papel da instituição de Educação Infantil enquanto um órgão socializador, formador de identidade, de opinião e transmissor de juízos de valor, no que diz respeito especificamente ao ensino de família. Optou-se por uma pesquisa qualitativa, e pelo uso da técnica de análise documental dos planos diretores de cinco instituições de Educação Infantil. Por meio dos resultados obtidos, especificamente sobre o ensino de família, constatou-se atividades que permitem a criança expressar a sua família vivida, contraditoriamente, atividades tradicionais, baseadas apenas na família nuclear, como a construção da árvore genealógica permanecem.
\end{abstract}

Palavras-chave: Família. Professores. Educação Infantil. Ensino. Crianças.

\section{A FAMILY RELATIONSHIP AND INSTITUTIONS OF EARLY CHILDHOOD EDUCATION: IMPLICATIONS ON THE TEACHING OF FAMILY FOR YOUNG CHILDREN.}

\begin{abstract}
This article is the result of a Master research that had as main objective to evaluate the concepts of family present in the master plans of Early Education Institutions, to know what educators think about the children's families and the value that they attribute interferes the family relationship and Child Education institutions. An attempt was also questioning the role of the institution of Early Childhood Education as a socializing agency, identity-forming, opinion and value judgments transmitter, specifically with regard to the teaching of family. We chose a qualitative research, and the use of document analysis techniques of master plans for five institutions Childhood Education. Through the results obtained, specifically on teaching family, we found activities that allow the child to express his family lived, contradictorily, traditional activities, based only on the nuclear family as the construction of the family tree remain.
\end{abstract}

Keywords: Family. Teachers. Early Childhood Education. Education. Children. 


\section{INTRODUÇÃO}

Esse trabalho constitui-se de um recorte de uma pesquisa de mestrado intitulada "As concepções de família presentes nos planos diretores das instituições de Educação infantil: avanços, contradições e possibilidades", aprovada pelo comitê de ética e pesquisa da FCT-UNESP, como consta o protocolo 73/2011. Está investigação defende a parceria entre a instituição familiar e as instituições de Educação Infantil como indispensável para a qualidade da Educação, complexa e desafiadora, assim como, um direito da criança e de sua família garantido pelas leis brasileiras e documentos oficiais referentes à Educação Infantil, tais como a Constituição (BRASIL, 1988); LDB (BRASIL, 1996); Diretrizes Curriculares Nacionais (BRASIL, 2009); Referencial Curricular Nacional para a Educação Infantil (BRASIL, 1998).

A relevância da parceria entre as instituições de Educação Infantil e as famílias para garantir a qualidade da educação oferecida às crianças, motivou esta pesquisa a ter como foco de estudo as instituições de Educação Infantil, tendo ainda como outra razão, o fato de ser esse nível de educação em que a proximidade com as famílias dos educandos é maior, devido ao próprio cotidiano dessas instituições e as necessidades específicas da criança pequena.
A pesquisa se caracterizou pela metodologia qualitativa, o que se justifica pelo fato de surgir da necessidade de responder inquietações particulares, elucidando uma realidade complexa e contextualizada que não pode ser quantificada. (MINAYO, 2002. p.21-22), se refere à pesquisa qualitativa da seguinte forma: "Ela trabalha com o universo de significados, motivos, aspirações, crenças, valores, atitudes, o que corresponde a um espaço mais profundo das relações, dos processos e dos fenômenos que não podem ser reduzidos à operacionalização de variáveis".

Dentro da abordagem qualitativa essa pesquisa se encaixa no tipo estudo de caso, pois tem como foco as escolas de educação infantil da cidade de Presidente Prudente-SP. Nas palavras de Ludke e André os estudos de caso:

Enfatizam a "interpretação em contexto". Um princípio básico desse tipo de estudo é que, para uma apreensão mais completa do objeto, é preciso levar em conta o contexto em que ele se situa. Assim para compreender melhor a manifestação geral de um problema, as ações, as percepções, os comportamentos e as interações das pessoas devem ser relacionados á situação específica onde ocorrem ou á problemática 
determinada a que estão ligadas. (LUDKE E ANDRÉ, 1986 p.18-19).

Por meio do uso da técnica de análise documental analisamos as informações sobre famílias contidas nos cinco planos diretores de instituições de Educação Infantil que atendem crianças de três a cinco anos, uma de cada região (norte, sul, leste, oeste, central) do município de Presidente Prudente-SP. A mesma teve como objetivo central identificar as concepções dos educadores infantis sobre as famílias das crianças para averiguar se elas contribuem ou dificultam o relacionamento satisfatório entre as instituições de Educação Infantil e as famílias no alcance dos objetivos educacionais.

Como objetivos específicos esta pesquisa buscou averiguar se as concepções dos educadores infantis, sobre as famílias de suas crianças, estão em consonância com a realidade dessas famílias investigando como as tais estão organizadas. Também nos preocupamos em saber como os professores ensinam o que é família. Na intenção de investigarmos quais os objetivos, conteúdos e metodologias que os docentes utilizam para ensinar "família" nos voltamos para o teor dos planos de ensino que compõem o plano diretor.

Neste trabalho, especificamente, temos a intenção de problematizar o ensino do que é a família hoje para as crianças pequenas e provocar reflexões a partir dos resultados obtidos por meio desta investigação.

\section{A família contemporânea}

A família na atualidade é valorizada como instituição formadora dos membros mais jovens, preparando-os para cumprir seus deveres e assim contribuir para a permanência e melhoria da sociedade, de sorte que sua influência moral, afetiva, cognitiva sobre os indivíduos que a compõem, principalmente os mais imaturos, não pode ser ignorada. No entanto, são reconhecidas as dificuldades de muitas famílias na realização de seu papel de educar as crianças pequenas.

Para que a família pudesse ter condições de cumprir o seu papel formador e ir ao encontro das expectativas sociais, valorativas e religiosas, fez se necessário construir um modelo familiar ao qual os indivíduos fossem capazes de admirar e seguir.

Segundo Souza (2006), essa família idealizada ascende juntamente com a burguesia na modernidade e possui características bem definidas e permanentes. A primeira delas se refere a sua formação, que só pode acontecer de pleno acordo com os valores morais e religiosos vigentes. Um homem e uma mulher por amor se unem 
mediante a uma cerimônia religiosa e civil, tendo como objetivos a serem alcançados a felicidade, permanecerem juntos enquanto viverem e a procriação dos descendentes.

A divisão dos papéis e funções dos membros da família são pré-determinados. 0 homem (marido e pai) é o responsável por prover todas as necessidades da família por meio do trabalho fora do lar. A mulher (esposa e mãe) tem como principal função a educação das crianças e servir ao marido e à organização da casa. Às crianças cabem estudar e brincar.

Essa idealização da família nuclear está "livre" de conflitos, os fatores históricos, sociais, políticos e emocionais não interferem na harmonia do lar.

A família nuclear ainda hoje se mantém hegemônica, no que se refere a sua rígida estrutura, pai, mãe e filhos, o mesmo não pode ser dito sobre a questão do domínio, divisão de trabalhos e papéis que começaram a ser questionados com a entrada da mulher no mercado de trabalho, ocasionando uma instabilidade, uma maior flexibilidade nos relacionamentos familiares e uma constante renegociação dos projetos individuais e grupais que envolvem a família.

Mesmo com as mudanças que a instituição familiar tem enfrentado, o modelo de família, representado pela nuclear, ainda predomina no imaginário coletivo de nossa sociedade como o "mais correto", sendo sua idealização transmitida por diversos âmbitos educativos como a mídia, escola, igreja, de pais para filhos etc. Segundo Calderón e Guimarães (1994), isso ocorre porque a família faz parte dos padrões culturais da nossa sociedade.

Apesar da idealização da família, no contexto histórico que vivenciamos, as novas configurações familiares crescem em número e saem da clandestinidade, nos desafiam a aceitá-las e respeitá-las como formas de ser e de se viver a família. A aceitação das mesmas geralmente causa certo desconforto, pois implica num desequilíbrio da ordem social, por representar a quebra de tradições, de valores arraigados desde a modernidade.

As mudanças rápidas e intensas da instituição familiar desafiam os educadores infantis a também transformarem o ensino sobre a família.

\section{Ensino do que é família.}

Considerando o aumento significativo do número de famílias, pós nucleares, cuja estrutura e as formas de organização se contrapõem ao modelo nuclear, nos perguntamos: como as instituições de Educação Infantil ensinam o que é ser família?

Analisamos os planos de ensino, contidos nos planos diretores, para conhecer a forma como esses educadores têm ensinado as crianças sobre o que é ser 
família, na atualidade, se consideram ou não as novas configurações familiares ao pensarem nos objetivos, nos conteúdos a serem discutidos, na metodologia, e, por fim, na forma de avaliarem a aprendizagem das crianças, referente a essa temática.

Partimos do pressuposto que a instituição de Educação Infantil é um importante órgão socializador, formador de identidade, de opinião e transmissor de juízos de valor, no que diz respeito especificamente à concepção e ensino de família. Os educadores ao apresentarem a sua concepção pessoal de família às crianças interferem na compreensão do que é família que as mesmas já possuem, construídas com base na realidade de suas famílias, o que pode acarretar num choque de concepções, valores e expectativas sobre a instituição familiar.

O plano de ensino do eixo temático Natureza e Sociedade, que compõe todos os planos diretores, faz referência ao ensino do que é família. O tema "família" está disposto no plano de ensino da Instituição de Educação Infantil (I.E.I.) Norte da seguinte maneira:

Objetivos específicos:

- ter a capacidade de perceber-se como ser social, que possui uma história, vinculada à história de seus familiares. Conteúdos:

- família. Atividades: a família e o seu funcionamento.

Registrar

em

desenhos

a

composição do grupo

familiar; - conversar com os pais para reconhecer as atividades a que se dedicam e o trabalho que realizam. (SECRETARIA MUNICIPAL DE EDUCAÇÃO, 20102012, p. 200-201).

Este trecho comprova que esses educadores se preocupam em ensinar as crianças a respeito do que é ser família. Para esses autores, o ensino do que é ser família é importante porque 0 aluno quando compreende a história da sua família entende a sua história pessoal. Outros pontos positivos deste plano de ensino são as atividades. Os educadores não definem com precisão o que é família, não apontam um modelo. É proposta uma atividade em que a criança é convidada a desenhar a família que possui e a perguntar para os pais quais são os seus trabalhos. A criança ao ter a oportunidade de representar sua família sente que a mesma é valorizada, o seu contexto vivido é considerado pela escola.

No plano diretor da I.E.I. Sul, localizamos as seguintes informações:

Objetivos específicos:Identificar papéis sociais vividos no convívio com a família, escola e 
comunidade. -Saber situar-se dentro da família. Conteúdo:Identidade - trabalhar o "eu" e a história do seu nome. -Família. Reconhecimento de si próprio como membro da família. Reconhecimento de si mesmo e do outro. Percepção da existência de diferentes modelos de família. -Composição familiar. Atividades:Confecção do livro da vida. -Pesquise as músicas de ninar que a família cantava para você. -Pinte o que você usava quando bebê. -Observe os variados tipos de família e diga qual é a família parecida com a sua. -Recorte e cole figuras de pessoas formando sua família, baseando na sua real família. - Pesquise quais são os membros de sua família-Monte a árvore genealógica de sua família, com a ajuda de um adulto. (SECRETARIA MUNICIPAL DE EDUCAÇÃO, 20102012, sem página).

Neste referido plano diretor, podemos nos atentar para o fato de que seus autores também consideram importante que as crianças conheçam a história de sua família para conhecerem melhor a si próprios, reconhecem que a família mudou e que, na atualidade, apresenta "diversos modelos de família".

A composição familiar de cada criança é ressaltada com o intuito de levar as crianças a perceber as transformações e permanências, seja em sua família ou no meio social em que vive.

Chama-nos a atenção as atividades que envolvem o ensino de família, quando os professores trazem para discutir com as crianças várias formas de ser família e pedem as mesmas que digam qual se parece com a sua, incitam para que a própria criança recorte figuras de pessoas e forme sozinha, como acha que é a sua família, e mais que pesquise em casa com a sua família quais são seus membros. Tais atividades demonstram sensibilidade para o fato de as crianças possuírem diversas famílias e não só o modelo nuclear, ainda socialmente vigente o que denota um avanço na maneira de ensinar o que é família. Não apresentam a família como uma instituição pré-definida, com base num modelo social que deva ser seguido, antes permitem que a criança apresente a sua definição de família e por meio de suas escolhas metodológicas consideram todas essas formas de se organizar e ser das famílias.

As referidas atividades pedagógicas valorizam os conhecimentos prévios das crianças sobre o que é família, levam em 
consideração os seus sentimentos para com seus membros familiares, apresentam as diversas formas de ser e de se organizar das famílias contemporâneas. Esta maneira de conduzir o trabalho pedagógico, com o tema família, não constrange as crianças que possuem famílias pós-nucleares.

A única atividade que pode fragilizar o ensino sobre família é a proposta de construção da árvore genealógica. Se esses educadores reconhecem que a família mudou, que algumas das crianças possuem famílias que não se encaixam na estrutura nuclear, porque pedir tal atividade? Acreditamos que os professores tenham uma intenção séria com este trabalho, não obstante, o que fazer quando não se conhece a identidade do pai ou da mãe e nem tampouco dos seus antepassados? A proposição deste tipo de exercício pode constranger e requerer uma atenção especial do professor no sentido de considerar e respeitar os diferentes arranjos familiares.

É uma atividade, portanto, desnecessária não só para a criança como para o adulto que vai ajudá-la, pois sem dúvida pode levar o mesmo a sentir culpado por não oferecer a "família" capaz de se encaixar no modelo tradicional "nuclear" à criança amada. Atividades que consideramos tradicionais no ensino de família como a construção da árvore genealógica foi pensada com base na existência do modelo de família nuclear.

No plano diretor da Instituição de Educação Infantil Oeste, os autores reconhecem a família como um tema importante para ser trabalhado, mas não apresentam claramente como fazer isso:

Conteúdos: Março:- a
criança (a criança e o
eu, a criança e a
família, a criança e a
escola, direito e
deveres); Maio:- dia
das mães (a
importância na função
dentro e fora do lar,
como a criança pode
ajudá-la com a sua
participação,
características físicas
e psicológicas).
(SECRETARIA DE
MUNICIPAL 2010-
EDUCAÇÃO,
2012, p. 196-197).

O tema família consta no conteúdo. Neste quesito é ressaltada a importância das mães, do seu papel social. Os educadores se preocupam em ensinar como a criança pode ajudar a mãe. Com relação aos papéis sociais desempenhados pela mãe é oportuno refletir sobre as considerações de Carvalho ao admitir que alguns educadores ainda "desconhecem as mudanças nas formas de organização familiar que vêm distanciando um grande número de famílias do modelo de família patriarcal em que a mãe se dedica 
integralmente aos filhos e à vida familiar" (CARVALHO, 2000, p.149).

$\mathrm{Na}$ I.E.I. Leste faz-se a seguinte proposta de trabalho:

Objetivos:- resgatar a importância da mãe no contexto familiar. Conteúdos: Dia das mães. Metodologia:- confecção de cartão para as mães. (SECRETARIA MUNICIPAL DE EDUCAÇÃO, 2010 - 2012, p. 124-125).

\section{$\mathrm{Na}$ Instituição de Educação Infantil} Leste, o foco do ensino sobre família é referente à comemoração do dia das mães: “resgatar a importância da mãe no contexto familiar; Dia das mães; - confecção de cartão para as mães" (SECRETARIA MUNICIPAL DE EDUCAÇÃO, 2010 -2012, p.124).

Mesmo a I.E.I. tendo um objetivo tão nobre de homenagear os familiares de suas crianças é preciso repensar maneiras alternativas de manifestar o afeto e o respeito a um ente querido.

A instituição de Educação Infantil, ao realizar eventos comemorativos como esse, parece se render aos interesses econômicos da sociedade capitalista, que inventa certas datas para vender e ter mais lucro.

Como se sentem as crianças que não possuem mãe? Ou porque as mães faleceram ou as abandonaram pelas mais diversas razões. Ou até mesmo têm mãe, que não pode estar presente porque trabalha também fora do lar. Certamente mesmo que as crianças possuam outros cuidadores, para elas iguais em importância, podem se sentir triste com este tipo de evento "dia das mães" e se recusarem a "comemorar", sentindo-se excluídas por serem diferentes. Infelizmente, a escola não lhes dá direito de escolha, essas atividades geralmente, são dirigidas a todos.

Uma forma de evitar situações como essas é que a escola convidasse "a família", envolvendo todos os seus membros sem discriminar o papel social de um membro específico.

No plano diretor da I.E.I. Central o tema família comparece da seguinte maneira:

Objetivos específicos:ter a capacidade de perceber-se como ser social, que possui uma história, vinculada a história de seus familiares.

Conteúdos:- Família. Atividades:- a família e 0 seu funcionamento.

Registrar em desenhos a composição do próprio grupo familiar. - conversar com os pais para reconhecer as atividades a que se dedicam e o trabalho que realizam. (SECRETARIA MUNICIPAL DE EDUCAÇÃO, 2010 2012, p.7). 
Neste plano de ensino é interessante a possibilidade dada à criança para se expressar, por meio do desenho, como é a sua família, incentivando-a a obter mais informações sobre a mesma conversando com os pais.

\section{CONCLUSÃO}

O fato de encontramos, nos planos de ensino das Instituições de Educação Infantil Norte, Sul, Central atividades pedagógicas que ensinam as crianças sobre o que é família de forma a permitir que expressem as suas estruturas familiares, revela que os educadores estão conscientes de que não existe um modelo de família universal.

Ao ensinar o que é família como base no modelo idealizado, o nuclear, ou não ser capaz de englobar nas suas discussões sobre o tema as novas configurações familiares, a instituição de Educação Infantil pode confundir as crianças, ao desconsiderar as suas famílias e influenciá-las a transformar as suas concepções pessoais de família.

Ao apresentar a família idealizada, a instituição de Educação Infantil transforma as outras variações de ser família em inadequadas, inferiores, contribuindo para que as crianças se tornem preconceituosas com relação às famílias pós-nucleares. A I.E.I. deveria, na verdade, apresentar a instituição familiar de forma crítica, que se transforma historicamente para atender às necessidades humanas.

As atividades que expressem situações que atualmente são comuns no cotidiano familiar, como, por exemplo, a união de pais com diferença de idade, o convívio com os idosos, são relevantes para complementar o ensino do que é família na atualidade.

Práticas como essas contribuem para que as crianças tenham a oportunidade de conhecerem melhor a si mesmas e o mundo social em que vivem, objetivo, que segundo os educadores, deve ser alcançado pela disciplina natureza e sociedade.

\section{REFERÊNCIAS}

BRASIL. Constituição (1988). Constituição da República Federativa do Brasil: promulgada em 5 de outubro de 1988. Organização do texto por Juarez de Oliveira. 4. ed. São Paulo: Saraiva, 1990. 168 p. (Série Legislação Brasileira).

Lei de Diretrizes e Bases da Educação Nacional. Lei no 9.394/96, de 20 de dezembro de1996.

BRASIL, Resolução CEB n. 95 de 17 de Dezembro de 2009. Fixa as Diretrizes Curriculares Nacionais para a Educação Infantil. Brasília: MEC/Secretaria.

BRASIL, Ministério da Educação e do Desporto. Secretaria de Educação Fundamental. Referencial Curricular Nacional para a Educação Infantil. Vol.1 Brasília: MEC/SEF, 1998. 
CALDERÓN, A. I; GUIMARÃES, R. F. Família: a crise do modelo hegemônico. São Paulo:Cortez, 1994.

CARVALHO, M.E. P. DE. Relações entre família e escola e suas implicações de gênero. Cadernos de Pesquisa, no. 110, julho/ 2000p. 143-155.

LUDKE, M.; ANDRÉ, M.E.D.A. Pesquisa em educação: abordagens qualitativas. São Paulo: E.P.U. 1986.

MINAYO, M.C. S. Pesquisa social: teoria, métodos e criatividade. 21 ed. Petrópolis: Vozes, 1993.

SECRETARIA MUNICPAL DE EDUCAÇÃO, Planos Diretores, instituições de Educação infantil Sul, Leste, Norte, Oeste e Central. Presidente Prudente, 2010-2012.

SOUZA, M. R. Configurações plurais. In: Revista mente e cérebro. São Paulo: Duetto, 2006, p.52-65.

Recebido para publicação em 10/08/2014

Revisado em 26/08/2014

Aceito em 09/09/2014 